\title{
7 Getting Help and Support
}

The Open BTEC learning materials have been carefully designed to allow you to be as independent as possible in your studies. Inevitably though, there will be times when you feel you need additional help. This might be to help clear up a misunderstanding or difficulty arising from the learning materials or maybe simply to reassure you that you are on the right track.

All learning centres participating in the Open BTEC scheme will be offering a range of opportunities for you to consult your tutors in face to face meetings or by telephone. In some cases a number of students from a single organisation have joined the course as a group, and additional tutorial support will be available from their own training officers. Whatever the pattern, you will be told about the details when you first join the course and these will appear on the Study Plan.

\section{Self-help Groups}

Some students are perfectly happy to work most of the time on their own. Others prefer frequent contact with fellow students where this is possible. One way to achieve this as a student on an open learning course is to set up a 'self-help' group of fellow students. These, where they exist, are entirely voluntary, but your learning centre may ask if you are willing to release your address and telephone number to other students in return for theirs. It must be emphasised though that this will only be done with your written permission.

\section{How You Can Help Open BTEC}

Good open learning materials are subject to regular revision to take into account new developments in the subject area covered, and to improve their effectiveness as learning aids.

While you are undertaking your studies as an Open BTEC student, you will be in a very good position to judge the effectiveness of the learning materials and methods as you use them.

Open BTEC is always pleased to have comments from students, perhaps including suggestions for improvements to the materials, perhaps pointing out activities or reading which proved to be particularly enjoyable.

If you wish to provide feedback or if you have any other comments to make, tell your tutor who will pass them on, or write direct to:

\author{
Open BTEC \\ Central House \\ Upper Woburn Place \\ London WC1H OHH
}

Remember - the right word or two from you can help save further generations of students from the difficulties you may have identified. 